\title{
Determination of $\mathrm{LD}_{50}$ Value of Vigna radiata (L.) Wilczek Cultivar- Naval
}

\author{
Amol Chandrakant Vikhe, ${ }^{1, *}$, Janardhan Namdeo Nehul ${ }^{2}$ \\ ${ }^{1}$ Department of Botany, New Arts, University of Pune, India \\ ${ }^{2}$ Department of Botany, University of Pune, India
}

Received September 9, 2019; Revised November 27, 2019; Accepted December 16, 2019

Copyright $\odot 2020$ by authors, all rights reserved. Authors agree that this article remains permanently open access under the terms of the Creative Commons Attribution License 4.0 International License

\begin{abstract}
Vigna radiata (L.) Wilczek is an important legume crop in India for Food as well as Fodder Purpose, enriched with good Proteins, Carbohydrates, Vitamins and Minerals. The demand of Vigna radiata is high in market today, so there is a need to enhance the productivity and area under cultivation. The Mutation Plant Breeding is the most popular, widely used and globally accepted method to improve the cultivars for high yield, early maturity, drought, salinity, heat, insect, disease tolerant/resistant, high nutritional and low antinutritional factors. Mutagens like; Ethyl Methane Sulphonate, Sodium Azide, Gamma Irradiation are used in Mutation Breeding to create variability. The present study has been carried out on the Vigna radiata, Cultivar-Naval. The first stage in the research was the determination of $\mathrm{LD}_{50}$ Value of the Cultivar Naval. It was carried out with different concentrations and time of intervals with mutagens like; EMS, SA and GR with including control as nil (without treatment). The parameters were studied in accordance with the International Seed Testing Association (ISTA) rules. The results showed variation in the studied parameters as compared to control.
\end{abstract}

Keywords Vigna Radiata, EMS, SA, Gamma Radiation, $\mathrm{LD}_{50}$ Value

\section{Introduction}

Vigna radiata (L.) Wilczek $(2 \mathrm{n}=22)$, is the member of Leguminosae family, cultivated throughout the world including India, Pakistan, China, Nepal, Bangladesh, Myanmar, Malaysia, Thailand, Indonesia and Srilanka. Recently its cultivation has been started in USA and Africa. India is the largest producer in the world to cultivate Mungbean. Day by day, the area under Mungbean Cultivation is increasing in the world. Vigna radiata is cultivated throughout the year, i.e. Kharif, Rabi and Summer season.

During 2017-2018, the total coverage under mungbean was about 41 Lha with a production of 19 Lt. There has been phenomenal increase in area of mungbean in the country from 2015-2016 onwards. Rajasthan with more than 42 percent area and 39 percent of production in the total mungbean contribution in the country. According to report, more than 80 percent of mungbean production comes from 10 states of Rajasthan, Madhya Pradesh, Maharashtra, Bihar, Karnataka, Tamilnadu, Gujarat, Andhra Pradesh, Odisha and Telangana (DES, Ministry of Agri. \&FW (DAC\&FW), Govt. of India; 2017-18-IIIrd Adv. Est.

Genetic improvement through Mutation Breeding has broad scope in agriculture sector to develop new varieties which are resistant/ tolerant to disease, insect, drought, salinity, heat, pest with high nutritional and low antinutritional factors. EMS, SA and GR mutagens create great variability in plant materials as compared to other mutagens. Therefore, we have selected these mutagens for this study. The cultivar Naval is commercially and widely cultivated in Maharashtra. It is not suitable in summer season, susceptible to drought and salinity.

The Gamma rays has been widely used for the improvement of various traits of crops (Khatri et al., 2005; Tah, 2006; Songsri et al., 2011; Aney, 2013). The Sodium azide concentrations affect the biological parameters (G. Roopa Lavanya et al., 2011). Chlorophyll mutations can be induced by Ethyl Methane Sulphonate (Bhal and Gupta 1982).

The effect of Mutation rates depends on the dose of that chemical concentration and time for soaking which is applied on seed material. The minimum lethal dose is 50 percent; i.e. out of 100 seeds 50 percent of seeds should be germinated and mortality is 50 percent. Hence we must to know the $\mathrm{LD}_{50}$ value of that species. A dose that causes $50 \%$ mortality and $50 \%$ of seeds can be survived. 
The LD50 value is different between species and varieties in a species. For example, the $\mathrm{LD}_{50}$ of $\mathrm{K}-851$ Mungbean cultivar is $54.06 \mathrm{kr}$ and for Sona is 53.20 (Tah, 2006) for Gamma Irradiation. Therefore, this study was carried out to determine the $\mathrm{LD}_{50}$ of Vigna radiata Cultivar-Naval. In M2 Generation mutation frequency of Chlorophyll mutants and Leaf morphological changes should be observed. Quantitative traits like; Plant Height, Number of pods per plant, Pod Length, Seeds per pod should be observed. The transmitted characters in M3 Generation should be confirmed for Morphological and Biochemical Characterization.

\section{Materials and Methods}

Seeds selected for the present study of Vigna radiata (L.) Wilczek, commonly known as Mungbean were procured from Nirmal Seeds Pvt. Ltd. Pachora, Jalgaon. The cultivar is determinate in habit and not suitable for cultivation in summer season and widely cultivated in Maharashtra. Naval cultivar has distinguishing characters like medium time of flowering, dark green leaf colour, straight curvature of mature pod, long pod length, large seed size and number of seed/ pod is 12-14.

Ethyl Methane Sulphonate and Sodium Azide- Source of Chemicals EMS and SA (Sigma- Aldrich) were availed from Research Center Department of Botany, New Arts, Commerce and Science College Ahmednagar. The doses employed were $5 \mathrm{mM}, 10 \mathrm{mM}, 15 \mathrm{mM}, 20 \mathrm{mM}$ and $25 \mathrm{mM}$ of EMS, $1 \mathrm{mM}, 2 \mathrm{mM}, 3 \mathrm{mM}, 4 \mathrm{mM}$ and $5 \mathrm{mM}$ of SA. Gamma Irradiated seeds were treated with $\left(\mathrm{Co}^{60}\right) 150 \mathrm{GY}, 250 \mathrm{GY}$, 350GY, 450GY and 550GY from BARC Mumbai. Seeds without treatment were used as control. The experiment was conducted in the year 2018-2019 at Department of Botany, New Arts, Commerce and Science College Ahmednagar.

\section{Experimental Setup}

The seeds were pre-soaked in Distilled water for 2 hours. The pre-soaked seeds were dried and deepened in the prepared concentrations of EMS $(5 \mathrm{mM}, 10 \mathrm{mM}, 15 \mathrm{mM}$, $20 \mathrm{mM}$ and $25 \mathrm{mM}(2)$ and SA $(1 \mathrm{mM}, 2 \mathrm{mM}, 3 \mathrm{mM}, 4 \mathrm{mM}$ and $5 \mathrm{Mm}$ ) for 6 hours(4), Gamma Irradiated seeds with 150GY, 250GY, 350GY, 450GY and 550GY(2) seeds as a dry. Untreated seeds were kept as a control. After treatment period seeds were removed and washed 3 times with running distilled water and dried. The 200 seeds in each concentration including control were kept for germination in between paper method and paper with seeds were rolled with plastic paper covering sheet to maintain moisture content. The rolls were placed in an upright position and kept in germination chamber at $25 \pm 1^{\circ} \mathrm{C}$ temperature with relative humidity $80 \pm 1 \%$. The germination percentage was recorded on $5^{\text {th }}$ day after treatment period.

The parameters were calculated as per ISTA rules. The final percentage of seed germination and parameters were calculated using formula.

Percent Seed Germination $=\frac{\text { Number of Seeds Germinated (Normal Seedlings) }}{\text { Total Number of Seeds Kept for Germination }} \times 100$

\section{Result and Discussion}

The experiment on Vigna radiata Cultivar-Naval, to determine the $\mathrm{LD}_{50}$ Value of EMS, SA and GR treated seeds was carried out. The doses were prepared and seeds were treated with given concentrations. The EMS, SA and GR showed the significant effect on the seed germination. The categories of seedlings fall into normal seedlings, abnormal seedlings, fresh Ungerminated seeds, hard seeds and dead seeds. The control showed highest seed germination 83\% normal seedlings (Table-1., Fig.1). Less number of abnormal seedlings $11 \%$ (Table-1., Fig.2), were observed in control as compare to all other treatments. EMS-5mM dose Showed 76\% normal seedlings which is highest in the lower dose as compare to other treatments 70 , $64,54,46 \%$ in $10 \mathrm{mM}, 15 \mathrm{mM}, 20 \mathrm{mM}$ and $25 \mathrm{mM}$ (Table-1., Fig.1) respectively which is in decreasing order, similar results were obtained by Giri S. P. (2014). 46\% normal seedlings were observed in $25 \mathrm{mM}$ dose which is lethal i.e. the dose at which minimum $46 \%$ of seeds with normal seedlings. The Abnormal seedlings were observed high in $25 \mathrm{mM}$ dose is $34 \%$ (Table-1., Fig.2). The SA treatment with $1 \mathrm{mM}$ to $5 \mathrm{mM}$ showed normal seedlings $75,70,65$, 58 and $49 \%$ (Table-1., Fig.1) respectively. Same results were obtained by Lavanya R. G et al. (2011). The abnormal seedlings were observed more in $5 \mathrm{mM}$ dose is $34 \%$ (Table-1., Fig.2). The same results were obtained in Gamma Irradiated seeds, according to increasing order of treatment decreased the normal seedlings and increased abnormal seedlings. The dose 150GY, 250GY, 350GY, 450GY and 550GY (Table-1., Fig.1) showed normal seedlings $73,66,61,55$, and $49 \%$ respectively; the similar results were obtained by A. G Rukesh et.al. (2017). The highest abnormal seedlings were observed in dose 550GY is $26 \%$ (Table-1., Fig.2). All the treatments showed the minimum number of normal seedlings and high number of abnormal seedlings as compare to control. 
Table1 1. Determination of LD50 Value of Vigna radiata (L.) Wilczek Cultivar- Naval

\begin{tabular}{|c|c|c|c|c|c|c|c|}
\hline \multicolumn{8}{|c|}{ Determination of $\mathbf{L D}_{50}$ Value of Vigna radiata (L.) Wilczek Cultivar- Naval } \\
\hline Sr. No & Treatment & Conc. & $\begin{array}{c}\text { Normal } \\
\text { Seedlings }\end{array}$ & $\begin{array}{c}\text { Abnormal } \\
\text { Seedlings }\end{array}$ & $\begin{array}{c}\text { Fresh Ungerminated } \\
\text { Seeds }\end{array}$ & $\begin{array}{l}\text { Hard } \\
\text { Seeds }\end{array}$ & $\begin{array}{l}\text { Dead } \\
\text { Seeds }\end{array}$ \\
\hline 1 & Control & Nil & 83 & 11 & 5 & 0 & 1 \\
\hline \multirow{5}{*}{2} & \multirow{5}{*}{$\begin{array}{l}\text { Ethyl Methane } \\
\text { Sulphonate }\end{array}$} & $5 \mathrm{mM}$ & 76 & 19 & 1 & 0 & 4 \\
\hline & & $10 \mathrm{mM}$ & 70 & 21 & 3 & 0 & 6 \\
\hline & & $15 \mathrm{mM}$ & 64 & 25 & 3 & 0 & 8 \\
\hline & & $20 \mathrm{mM}$ & 54 & 32 & 4 & 1 & 9 \\
\hline & & $25 \mathrm{mM}$ & 46 & 34 & 5 & 0 & 15 \\
\hline \multirow{5}{*}{3} & \multirow{5}{*}{ Sodium Azide } & $1 \mathrm{mM}$ & 75 & 16 & 6 & 0 & 3 \\
\hline & & $2 \mathrm{mM}$ & 70 & 18 & 6 & 0 & 6 \\
\hline & & $3 \mathrm{mM}$ & 65 & 21 & 4 & 0 & 10 \\
\hline & & $4 \mathrm{mM}$ & 58 & 27 & 2 & 0 & 13 \\
\hline & & $5 \mathrm{mM}$ & 49 & 34 & 1 & 0 & 16 \\
\hline \multirow{7}{*}{4} & \multirow{5}{*}{$\begin{array}{l}\text { Gamma } \\
\text { Radiation }\end{array}$} & 150GY & 73 & 16 & 10 & 1 & 0 \\
\hline & & 250GY & 66 & 18 & 14 & 1 & 1 \\
\hline & & $350 \mathrm{GY}$ & 61 & 18 & 16 & 3 & 2 \\
\hline & & 450GY & 55 & 23 & 19 & 0 & 3 \\
\hline & & 550GY & 49 & 26 & 20 & 2 & 3 \\
\hline & & $S D \pm$ & 10.887 & 6.772 & 6.356 & 0.894 & 5.106 \\
\hline & & $S E \pm$ & 2.72 & 1.69 & 1.59 & 0.22 & 1.28 \\
\hline
\end{tabular}

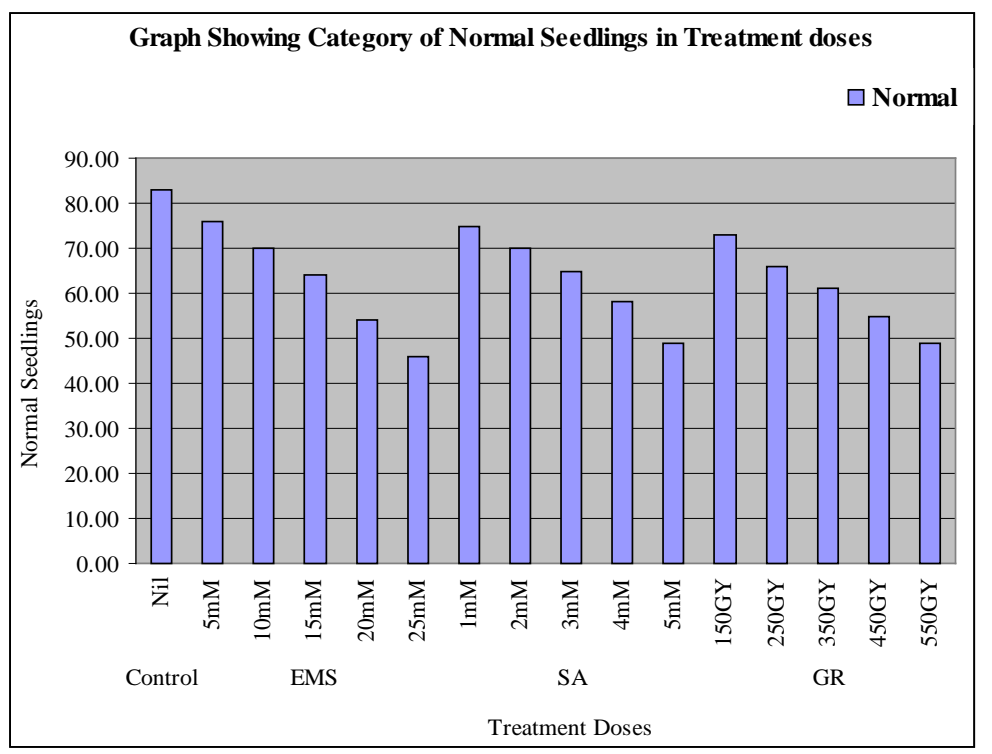

Figure 1. Normal Seedlings 


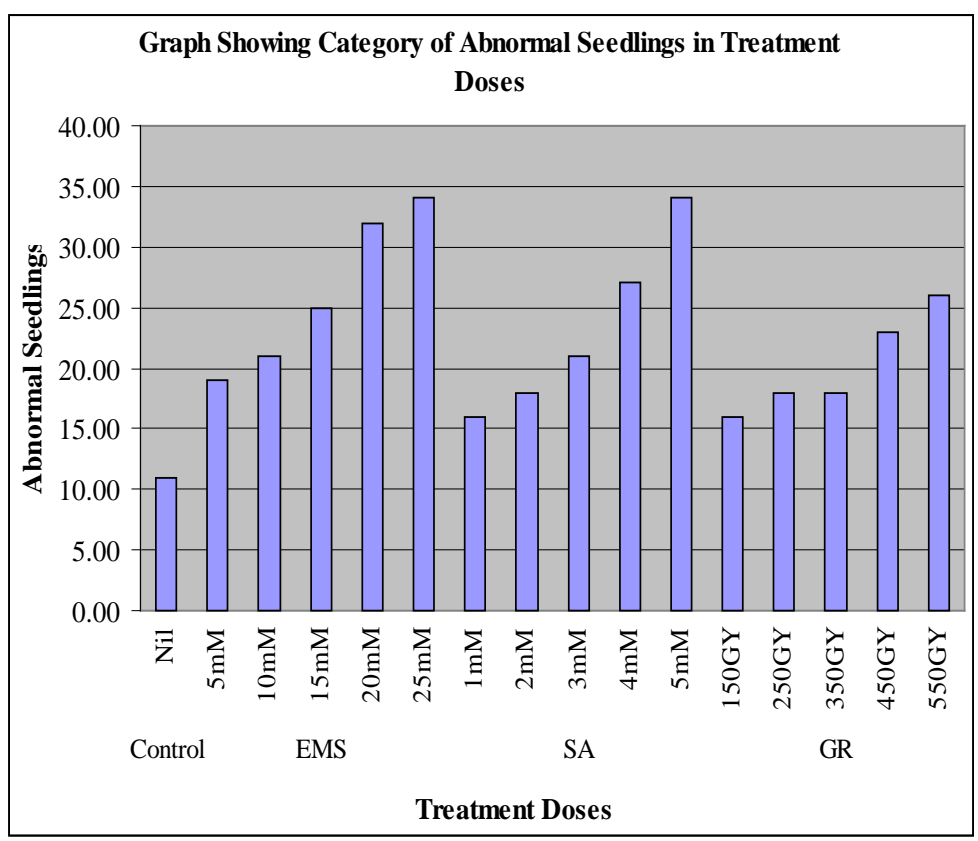

Figure 2. Abnormal Seedlings

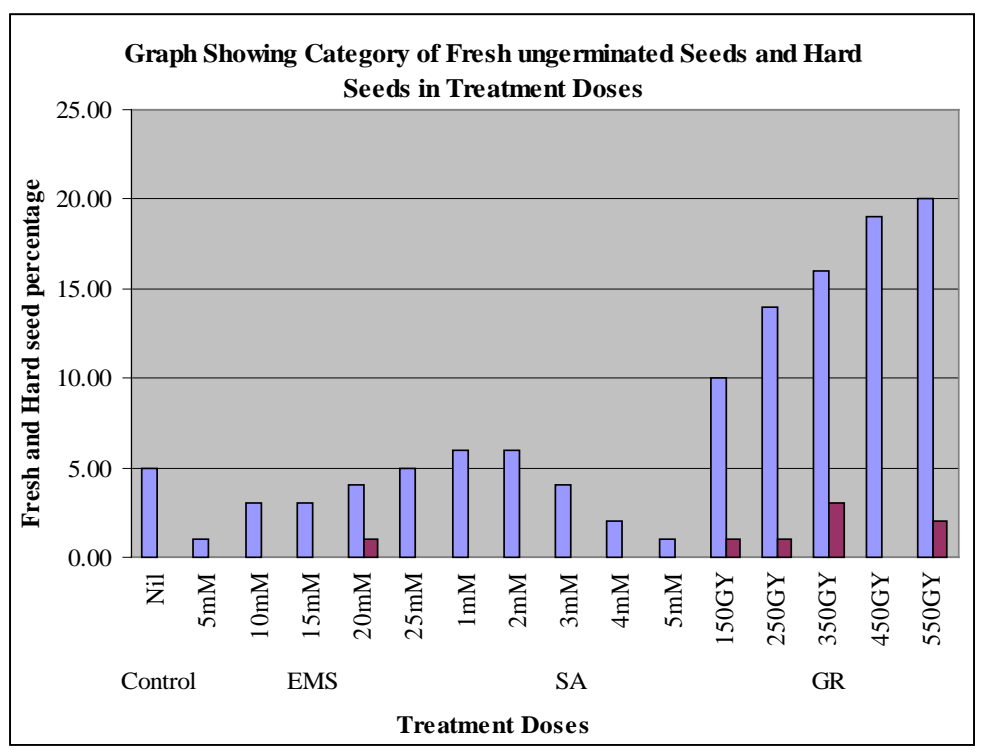

Figure 3. Fresh Ungerminated and Hard seeds 


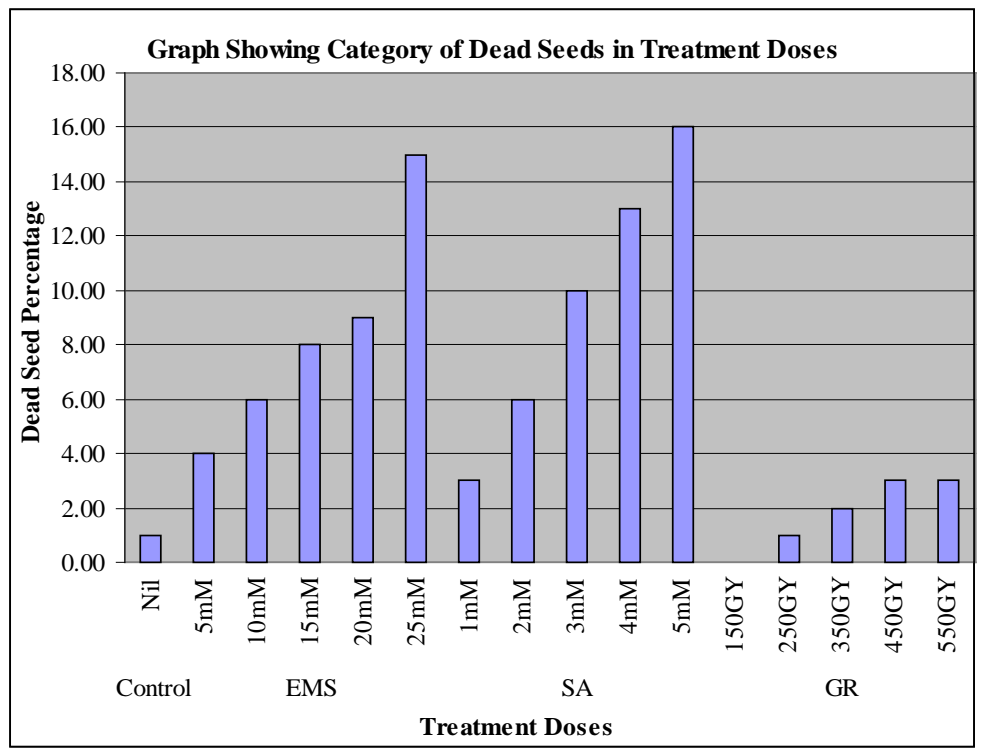

Figure 4. Dead Seed

\section{Conclusions}

In given experimental studies, $\mathrm{LD}_{50}$ Value of Vigna radiata Cultivar-Naval based on the survival of $50 \%$ of plants. The optimum dose was determined and these doses were selected for treatment. The sensitivity of cultivar-Naval to EMS, SA and GR were studied for germination as well as growth parameters including control. All the parameters were found significantly in all the doses of chemical treatments were studied. The study reveals that the EMS-10, 15 and $20 \mathrm{mM}$ dose were significant, SA-2, 3 and 4mM dose were significant and GR-250, 350 and 450GY dose were significant; hence we have selected these doses for treatment of seeds to investigate for further study.

\section{Photoplate}
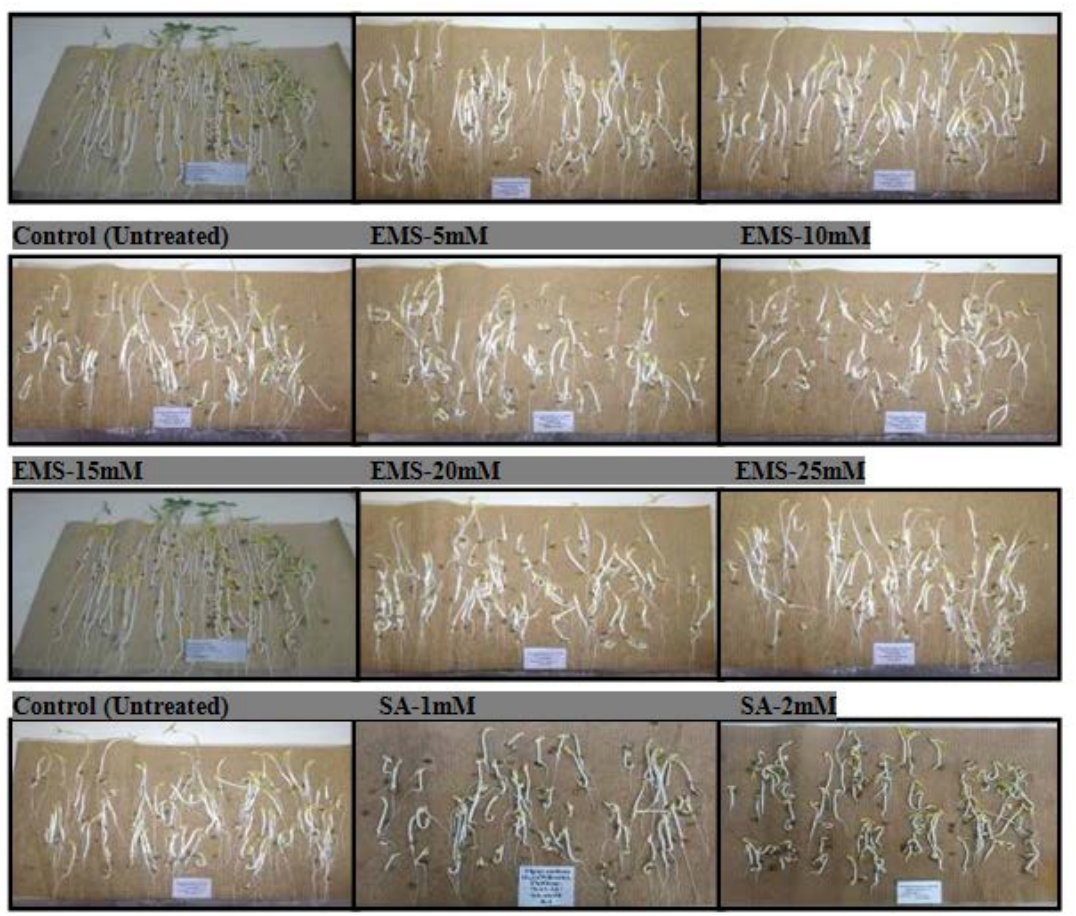


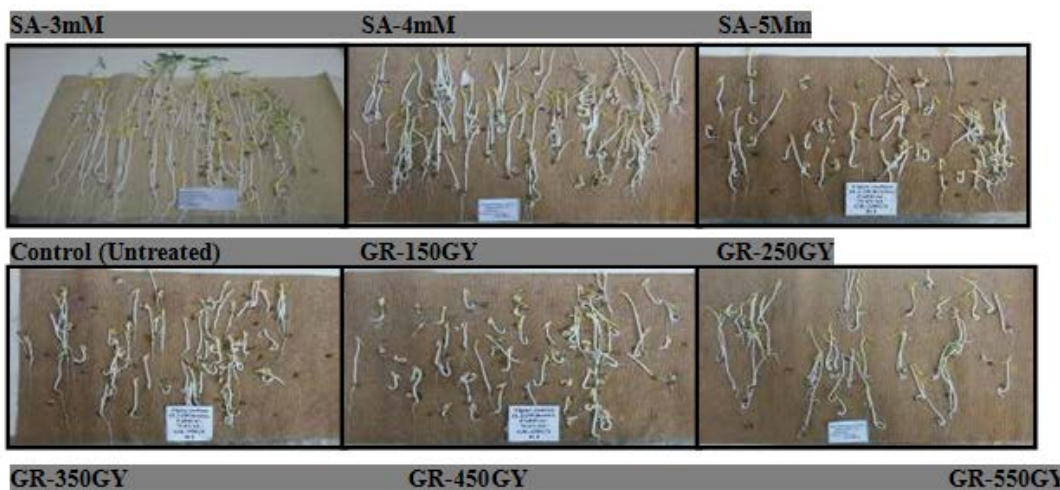

\section{REFERENCES}

[1] AG Rukesh, M Abdul Rahuman, S Christine L. and D Packiaraj (2017): Impact of gamma irradiation induced mutation on morphological and yield contributing traits of two genotypes of Green gram (Vigna radiata L.), Journal of Pharmacognosy and Phytochemistry, 6(6): 1229-1234.

[2] Anandhi Lavanya*, C. Vanniarajan, J. Souframanien and S. Ganeshram, (2017): Effect of Gamma Irradiation on F1 Seeds in Black gram (Vigna mungo (L.) Hepper), Journal of Cereals and Oilseeds, Plant Archives Vol. 17 No. 2, 2017 pp. 1533-1536, ISSN 0972-5210.

[3] Arunee Wongpiyasatid, Somsong Chotechuen et al., (2000): Induced Mutations in Mungbean Breeding: Regional Yield Trial of Mungbean Mutant Lines; Kasetsart J. (Nat.Sci.); 34:443-449.

[4] Bhal JR and Gupta PK (1983): Cytogenetics and origin of some pulse crops. In: Swaminathan MS, Gupta PK, Sinha U (Eds) Cytogenetics of Crop Plants, McMillan, India, pp 405-440.

[5] Dewi I. R*, Herman and Isro F. (2015): Lethal Dose 50 (LD50) of Mungbean (Vigna radiata L. Wilczek) Cultivar Kampar; SABRAO Journal of Breeding and Genetics 47 (4) 510-516, 2015.

[6] Dhirendra Khare and Mohan S. Bhale; Seed Technology Research Unit, Department of Plant Breeding and Genetics, J. N. Krishi Vishwa Vidyalaya, Jabalpur- 482004, MP, India.

[7] Giri S. P. (2014): Studies of Mutagenic Sensitivity in Pigeonpea [Cajanus Cajan (L.) Mill sp.], Bioscience Discovery, 5\{2): 227-229, July-2014, ISSN: 2229-3469(Pr int); ISSN: 2231-024X (Online).

[8] G.S. Dhulgande, D. A. Dhale et.al., (2011): Mutagenic Effectiveness and Efficiency of Gamma Rays and Ethyl Methanesulphonate in Pea (Pisum sativum L.), Journal of Experimental Sciences Vol. 2, Issue 3, Pages 07-08 [2011], ISSN: 2218-1768.

[9] K.S. Usharani* and C.R. Ananda Kumar, (2015): Research Note Mutagenic efficiency and effectiveness of gamma rays and EMS and their combination in inducing chlorophyll mutations in M2 generation of Urdbean (Vigna mungo (L.) Hepper), Electronic Journal of Plant Breeding, 6(1): 210-217 (Mar 2015) ISSN 0975-928X.

[10] Lavanya R, Yadav L, Suresh B, Abu G, Jyotipaul P (2011): Sodium azide mutagenic effect on biological parameters and induced genetic variability in mungbean. Journal of Food Legumes 24(1), 46-49.

[11] Mori Vaishali K.* Rajiv Kumar, Mori Kiran K. and K. H. Ribadiya, (2016): Ethyl Methyl Sulphonate and Gamma Rays Induced Mutation in Greengram (Vigna radiata (L.) R. wilczek), An International Quarterly Journal of Environmental Sciences, 75-80, 2016.

[12] M. D. Kakade and R.D. Borse (2017): Gamma Radiation Effects on Root, Shoot Length and Percent Germination of Alfalfa (Medicago Sativa L.), Advances in Bioresearch, Vol. 8 (4) July 2017: 80-83, ISSN: Print 0976-4585; Online ISSN 2277-1573.

[13] Sanjay G. Auti, (2012): Induced Morphological and Quantitative Mutations in Mungbean; Bioremediation, Biodiversity and Bioavailability; 6 (Special Issue 1); 27-39.

[14] Sushil Kumar, (2014): Gamma Radiation Induced Mutations in Mungbean (Vigna radiata (L.)Wilczek); Scholarly Journal of Agricultural Science Vol. 4(4), pp. 240-243 April, 2014; ISSN 2276-7118.

[15] S. Monica and N. Seetharaman (2017): Induced Chlorophyll and Viable Mutations in Lablab purpureus (L.) Sweet Var. typicus Through Gamma Rays and Ethyl Methane Sulphonate, International Journal of Pharma and Bio Sciences, Apr; 8(2): (B) 240-249, ISSN: 0975-6299. 